\title{
Ectasia following small-incision lenticule extraction (SMILE): a review of the literature
}

\author{
This article was published in the following Dove Press journal: \\ Clinical Ophthalmology \\ 15 September 2017 \\ Number of times this article has been viewed
}

\author{
Majid Moshirfar ${ }^{1,2}$ \\ Julio C Albarracin ${ }^{3}$ \\ Jordan D Desautels ${ }^{1,4}$ \\ Orry C Birdsong' \\ Steven H Linn' \\ Phillip C Hoopes Srl \\ 'HDR Research Center, Hoopes \\ Vision, Draper, ${ }^{2} J o h n$ A Moran \\ Eye Center, Department of \\ Ophthalmology and Visual Sciences, \\ University of Utah School of \\ Medicine, Salt Lake City, UT, \\ ${ }^{3}$ Department of Ophthalmology, \\ McGovern Medical School, University \\ of Texas Health Science Center at \\ Houston, Houston, TX, ${ }^{4}$ Department \\ of Ophthalmology, Warren Alpert \\ Medical School of Brown University, \\ Providence, RI, USA
}

Purpose: Four cases of corneal ectasia after small-incision lenticule extraction (SMILE) have been reported. In this review, we provide an overview of the published literature on corneal ectasia after SMILE and risk factors associated with this complication.

Methods: Case reports were identified by a search of seven electronic databases for pertinent heading terms between 2011 and July 2017. We identified patient characteristics and surgical details including preoperative topography, central corneal thickness, and anterior keratometry $(\mathrm{Km})$. Residual stromal bed (RSB) values not reported were computed using VisuMax ReLEx SMILE software Version 2.10.10. Preoperative ectasia risk was measured using the Randleman Ectasia Risk Score System (ERSS). Percent tissue alteration was calculated for each patient as described by Santhiago et al.

Results: Seven eyes of four patients developed corneal ectasia post SMILE. Two patients had abnormal topography in both eyes. One patient had abnormal topography in one eye. Only one patient was noted to have normal topography in both eyes and later developed ectasia in one eye in the absence of any known risk factors. The mean Randleman ectasia risk score was $4 \pm 3$ (range: $1-8$ ). The mean calculated percent tissue altered (PTA) was 38\% $\pm 6 \%$ (range: $30 \%-47 \%$ ). Conclusion: A majority of reported ectasia cases occurred in patients with subclinical keratoconus. These conditions may be exacerbated by SMILE and should be considered absolute contraindications to the procedure. Three patients were identified to have high risk based on the ERSS, and one patient exhibited a PTA $\geq 40 \%$. We formulated a modification to the current calculation of PTA that takes into account the differences in tissue altered between SMILE and laser in situ keratomileusis (LASIK). More studies are needed to fully quantify the risk of ectasia. For now, we propose adopting the same exclusion criteria used for LASIK in the SMILE procedure until more specific metrics have been validated.

Keywords: SMILE, small-incision lenticule extraction, ectasia, keratoconus, percent tissue altered, Ectasia Risk Score System

\section{Introduction}

After the US Food and Drug Administration (FDA) approval of laser in situ keratomileusis (LASIK), early laser platform users began reporting incidents of keratectasia. ${ }^{1,2}$ It was unclear whether these preliminary instances of ectasia were isolated consequences of a newly developed technology or the first of many cases to come. ${ }^{3}$ In the following years, the high volume of LASIK procedures performed revealed ectasia to be a persistent, albeit rare, postoperative complication. Detection of ectasia became easier as prognostic markers, such as the Randleman Ectasia Risk Score System (ERSS) and percent tissue altered (PTA), accrued in the literature and surgical predictability increased. To date, the prevalence of ectasia after LASIK has been estimated to be quite low, between $0.04 \%$ and $0.6 \% .{ }^{4}$ Nevertheless, the sensitivity of current risk
Correspondence: Majid Moshirfar HDR Research Center, Hoopes Vision, I I 820 South State Street, Suite 200, Draper, UT 84020, USA

Tel/fax + I 80I 5680200

Email cornea2020@me.com 
assessment modalities remains disputed due to the highly multifactorial nature of ectasia. ${ }^{5,6}$

Small-incision lenticule extraction (SMILE) is an alternative to LASIK that has demonstrated less dry eye symptoms, a lack of flap-related complications, and less injury to the subbasal nerve plexus. ${ }^{7-12}$ With the exception of a small side cut incision through which the refractive lenticule is extracted, SMILE preserves the collagen networks of the anterior stroma that account for $\sim 60 \%$ of the total corneal tensile strength. ${ }^{13,14}$ Even though SMILE is thought to reduce the probability of iatrogenic ectasia compared to LASIK, only four cases have been reported in the literature. ${ }^{15}$ In this review, we provide a concise summary of these cases and reiterate the importance of a conservative approach to performing SMILE on patients with suspicious topographies.

\section{Methods}

A literature review was performed using the following electronic databases: PubMed, Scopus, Ovid Medline, Embase, ScienceDirect, Google Scholar, and Cochrane Library. Publications were drawn between the dates of 2011 and July 2017. Key words used in the search queries included "ectasia" or "keratoconus" and "small incision lenticule extraction" or "SMILE" or "ReLEx SMILE". There were no language restrictions.

We reviewed patient characteristics information including age, sex, manifest refraction, cylinder, and spherical equivalent. Preoperative information such as topography, central corneal thickness (CCT), and anterior keratometry $(\mathrm{Km})$ was also noted. The preoperative risk of ectasia in reported cases was measured using the Randleman ERSS.

Two of the case reports did not include parameter data such as cap diameter, cap thickness (CT), optical zone, and maximum lenticule thickness (LT). ${ }^{16,17}$ In addition, three of the four patients did not have residual stromal bed (RSB) values reported. For these specific eyes, maximum LT and PTA were calculated using VisuMax ReLEx SMILE software Version 2.10.10 (Carl Zeiss Meditec AG, Jena, Germany), assuming the conventional parameters for a cap diameter of $7.10 \mathrm{~mm}, \mathrm{CT}$ of $120 \mu \mathrm{m}$, and optical zone of $6.50 \mathrm{~mm}$. RSB values were then calculated using $\mathrm{CT}$ and maximum LT subtracted from CCT.

\section{Compliance with ethics guidelines}

All procedures followed were in accordance with the ethical standards of the responsible committee on human experimentation (institutional and national) and with the 1964 Declaration of Helsinki, as revised in 2013.

\section{Results}

Seven eyes of four patients who underwent bilateral SMILE for myopia and myopic astigmatism correction were noted to develop ectasia. ${ }^{16-19}$ The mean refractive error was $-3.56 \pm 2.11$ (range: -1.5 to $-6.75 \mathrm{D}$ ) with a mean cylinder of $-1.12 \pm 0.38$ (range: -0.5 to -1.25 ). The mean manifest refraction spherical equivalent (MRSE) was $-4.13 \pm 2.08$ (range: -2.25 to -7.25 ). Preoperative patient characteristics and lenticule parameters are listed in Tables 1 and 2, respectively.

Cases of post-SMILE ectasia were reported in China, Egypt, Finland, and India. All patients were male with an average age of $26 \pm 5$ years (range: 19-33 years). None of the patients studied reported a family history of keratoconus. The mean preoperative CCT was $520 \pm 29 \mu \mathrm{m}$ (range: 513-559 $\mu \mathrm{m})$. All patients had preoperative corrected distance visual acuity (CDVA) of 20/20 or better. The mean reported preoperative anterior Km was 42.28 \pm 1.6 (range: 40.4-45.1). The mean calculated RSB was $321 \pm 35$ (range: 288-389). The mean Randleman Ectasia Risk Score was $4 \pm 3$ (range: 1-8) with five eyes categorized as being at high risk and three eyes being identified as low risk for ectasia after LASIK. The mean calculated PTA was $38 \% \pm 6 \%$ (range: $30 \%-47 \%$ ) with six eyes having a PTA $<40 \%$ and two eyes having a PTA $>40 \%$. Based on proposed PTA safety thresholds, two eyes were recognized to be at high risk for ectasia.

Two patients were diagnosed with subclinical keratoconus in both eyes. One patient was diagnosed with unilateral mild keratoconus (OD) preoperatively and normal topography in the other eye (OS) that progressed to bilateral ectasia. ${ }^{16}$ The fourth patient had normal topography in both eyes preoperatively, which later progressed to unilateral ectasia (OS). ${ }^{19}$ Overall, five eyes of the four patients displayed abnormal preoperative topographies but underwent SMILE nevertheless. The diagnosis of postoperative ectasia in these patients was made in an average of 6.4 months (range: $1-12$ months) after surgery.

\section{Discussion}

SMILE is believed to have less of a biomechanical impact on the integrity of the cornea than LASIK. ${ }^{20,21}$ Tissue removal in SMILE occurs much deeper than in LASIK, avoiding the interruption of the strong interweaving, steeper angles, and sheer stress of the anterior stroma. ${ }^{22}$ Specifically, SMILE is thought to result in greater stromal collagen stiffness and less deformations in the RSB when compared to LASIK. ${ }^{23}$ Although the theoretical risk of ectasia may be reduced, it is not completely eliminated due to the disruption of stroma that 


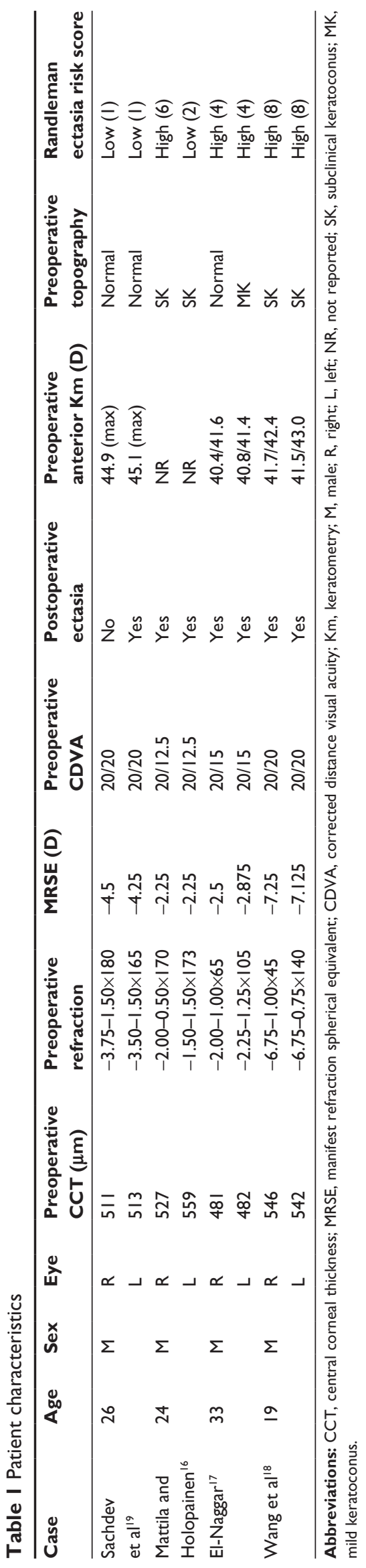

follows any refractive surgery. ${ }^{24}$ In the four cases described, preoperative abnormal topography was noted in three patients with post-SMILE ectasia. Ectasia occurred soon after surgery in these patients. This suggests that SMILE may not be suitable for patients exhibiting subclinical keratoconus, similar to LASIK. One case reported ectasia with normal preoperative topography, signifying that abnormal topography may not be the only risk factor for developing ectasia after SMILE.

An RSB of $<300 \mu \mathrm{m}$ is thought to be a risk factor for ectasia after LASIK. ${ }^{25}$ Although this principle has been applied to SMILE, practitioners currently do not know what the safety threshold for RSB should be. It has been hypothesized that leaving a thinner RSB may be a viable parameter for achieving higher myopic correction in SMILE. Practitioners who recognize the improved biomechanics of SMILE have proposed extracting a deeper lenticule and leaving a lower safety threshold RSB given the preserved integrity of the stronger anterior stroma. ${ }^{26}$ For example, an RSB of $220 \mu \mathrm{m}$ may be attainable with conservative estimations using a CT of $120 \mu \mathrm{m}$, comprising a corneal epithelium of $40 \mu \mathrm{m}$ and an anterior stroma of $80 \mu \mathrm{m}$. This would result in a theoretically unaltered stromal tissue of $380 \mu \mathrm{m}$, if the tensile strength of $80 \mu \mathrm{m}$ of anterior stroma is considered equivalent to that of $160 \mu \mathrm{m}$ of posterior stroma.$^{27}$ However, this hypothesis may not hold true given that patients in this review developed ectasia despite having an RSB of $>300 \mu \mathrm{m}$. Table 2 shows that five eyes had the safety threshold RSB within $\pm 10 \mu \mathrm{m}$.

The Randleman ERSS for LASIK incorporates a number of ectasia risk factors that may be relevant to SMILE. For example, the ERSS evaluates CCT, age, myopia, RSB, and topography to measure a patient's postoperative risk. ${ }^{28-30}$ Based on the data in Table 1, five out of eight ectatic eyes $(62.5 \%)$ in this review would have been identified as high risk by this system based on abnormal topography alone. Screening with this system would have likely precluded three patients from undergoing LASIK. Thus, the Randleman system may also have a practical use in the routine evaluation of patients before SMILE. Utilizing a calculated PTA, only two out of eight eyes (25\%) were classified as high risk. In these patients, the Randleman system was a more sensitive screening metric. Santhiago et al ${ }^{31-33}$ had previously reported that a PTA $>40 \%$ was more predictive of ectasia risk than moderate-to-high ERSS values for LASIK patients. Based on the cases reviewed, PTA alone may not be sensitive or specific enough for ectasia risk after SMILE. However, it should be noted that Santhiago et al applied this $>40 \%$ cutoff to patients presenting with normal topography. In patients with abnormal topography, such as those in this study, they suggested that 
Table 2 Pachymetric analysis of SMILE lenticule and corneal thickness alteration

\begin{tabular}{|c|c|c|c|c|c|c|c|c|c|}
\hline Case & Eye & $\begin{array}{l}\text { Cap diameter } \\
(\mathrm{mm})\end{array}$ & $\begin{array}{l}\text { CT } \\
(\mu \mathrm{m})\end{array}$ & $\begin{array}{l}\text { Optical } \\
\text { zone }(\mathrm{mm})\end{array}$ & $\begin{array}{l}\text { Side cut incision } \\
\text { angle (degrees) }\end{array}$ & $\begin{array}{l}\text { Max LT } \\
(\mu \mathrm{m})\end{array}$ & $\begin{array}{l}\text { RSB } \\
(\mathrm{mm})\end{array}$ & PTA (\%) & mPTA (\%) \\
\hline Sachdev & $\mathrm{R}$ & 7.10 & 110 & 6.0 & 48 & 85 & 304 & 38 & 23 \\
\hline et $\mathrm{al}^{19}$ & L & 7.10 & 110 & 6.0 & 48 & 82 & 305 & 37 & 22 \\
\hline Mattila and & $R$ & NR & NR & NR & NR & $50^{\mathrm{a}}$ & $357^{a}$ & 32 & 16 \\
\hline Holopainen ${ }^{16}$ & L & NR & NR & NR & NR & $50^{\mathrm{a}}$ & $389^{a}$ & 30 & 15 \\
\hline \multirow[t]{2}{*}{ El-Naggar ${ }^{17}$} & $\mathrm{R}$ & NR & NR & $N R$ & NR & $54^{a}$ & $307^{a}$ & 36 & 19 \\
\hline & L & NR & NR & NR & NR & $59^{a}$ & $303^{\mathrm{a}}$ & 37 & 20 \\
\hline \multirow[t]{2}{*}{ Wang et al ${ }^{18}$} & $R$ & 7.60 & 120 & 6.6 & 53 & 137 & $289^{a}$ & 47 & 32 \\
\hline & L & 7.60 & 120 & 6.6 & 53 & 134 & $288^{a}$ & 47 & 31 \\
\hline
\end{tabular}

Note: ${ }^{a}$ Calculated data.

Abbreviations: SMILE, small-incision lenticule extraction; CT, cap thickness; Max, maximum; LT, lenticule thickness; RSB, residual stromal bed; PTA, percent tissue altered; mPTA, modified percent tissue altered; R, right; L, left; NR, not reported.

the safety threshold for PTA in SMILE may be lower than that in LASIK, but no specific cutoff was endorsed. ${ }^{34}$

Currently, Santhiago ${ }^{35}$ has put forth a revised evaluation of PTA, specific for SMILE, which examines the relationship of the LT, CT, and CCT such that PTA $=(\mathrm{CT}+\mathrm{LT}) / \mathrm{CCT}$. From a conceptual basis, the amount of tissue altered in SMILE is less compared to that in LASIK. We believe that this notion necessitates the use of a correction factor to the original formula put forth by Santhiago et al. Vertical side cuts through the corneal lamellae are thought to weaken corneal structural integrity more than horizontal delamination incisions during LASIK flap creation. ${ }^{36}$ If this concept holds true for SMILE, the ratio of vertical incision between these two procedures can be determined. We began by computing the ratio of incision length to total circumference for each procedure as illustrated in Figure 1. For a LASIK flap diameter of $8.75 \mathrm{~mm}$, a hinge angle of $55^{\circ}$, and a flap circumference of $27.5 \mathrm{~mm}$, the actual LASIK flap incision length would be $23.3 \mathrm{~mm}$. Assuming a SMILE cap diameter of $7.5 \mathrm{~mm}$, smallincision angle of $90^{\circ}$, and cap circumference of $23.6 \mathrm{~mm}$,

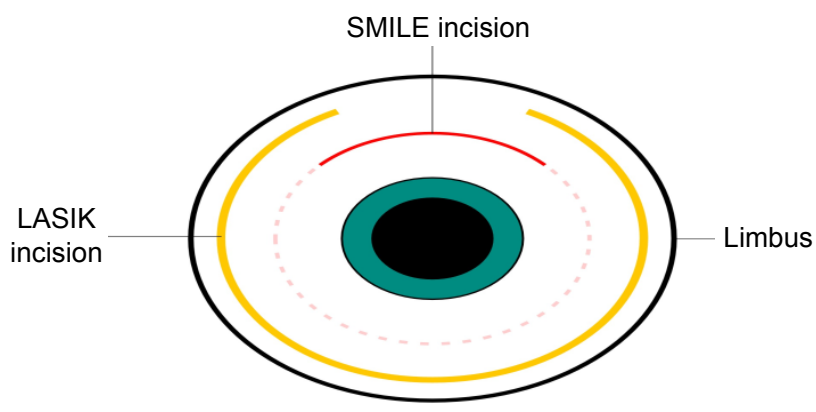

Figure I Schematic representation of SMILE incision and LASIK flap incision with respect to the corneal limbus.

Notes: SMILE cap circumference and small-incision length exhibited using a conventional diameter of $7.5 \mathrm{~mm}$ and hinge angle of $90^{\circ}$. LASIK flap circumference and flap incision length exhibited using a flap diameter of $8.75 \mathrm{~mm}$ and hinge angle of $55^{\circ}$. Abbreviations: SMILE, small-incision lenticule extraction; LASIK, laser in situ keratomileusis. the small-incision length would be equal to $5.89 \mathrm{~mm}$. The resulting ratio of small-incision length to total SMILE cap circumference $(S)$ would be 0.25 . Similarly, the ratio of LASIK flap incision length to total flap circumference $(L)$ would be 0.85 . Therefore, the ratio of $S / L$ would be equal to 0.30 . This ratio can be interpreted theoretically as SMILE inducing $70 \%$ less disruption of anterior corneal lamellae than LASIK for an identical myopic correction.

We offer a modified PTA (mPTA) formula that accounts for this difference in anterior corneal lamellae disruption between the two procedures using the ratio discussed earlier. This mPTA should be calculated using the formula, $\mathrm{mPTA}=[(S / L) \times \mathrm{CT}+\mathrm{LT}] / \mathrm{CCT}$, and the mean mPTA was found as $22 \% \pm 6 \%$ (range: $15 \%-32 \%$ ). Although no safety threshold PTA value for SMILE has been endorsed, we believe that an mPTA value of approximately $20 \%$ may be considered as high risk. If we apply this threshold to the patients in this study, five out of eight eyes $(62.5 \%)$ would have been identified as high risk. This threshold could be used to assess patient ectasia risk for SMILE and may even be lower in patients with abnormal topography. Still, we cannot say for certain that our modified formula will result in a PTA for SMILE that is sensitive or specific. More specific biomechanical data from post-SMILE ectasia cases are needed to fully delineate the association between PTA and the risk for postoperative ectasia.

\section{Conclusion}

We have reviewed four cases of postoperative ectasia following SMILE. Ectasia was found to be more common in patients with underlying corneal pathology but was also seen in a patient with normal topography. Thus, ectasia may be a risk inherently associated with the SMILE procedure. If implemented, the Randleman's criteria would have precluded three patients from undergoing SMILE, whereas 
PTA alone would have only identified one patient as high risk for ectasia. We propose that SMILE may cause $70 \%$ less disruption of the anterior corneal lamellae when compared to LASIK and offer a modified formula for PTA in SMILE. A low threshold for mPTA, approximately $20 \%$, could indicate a high risk for ectasia after SMILE. However, determination of an accurate calculation of PTA must be developed using data from patients who had ectasia after SMILE in the absence of risk factors.

There have been $>750,000$ cases of SMILE performed worldwide, and only four cases of ectasia have been reported. We currently lack the sufficient long-term follow-up evidence needed to thoroughly assess ectasia risk, but we assume that the risk will be similar to, if not less than, post-LASIK ectasia. Further studies should examine the patient characteristics that predispose individuals to develop ectasia after SMILE in the absence of risk factors and compare those to similar patients who developed ectasia following LASIK. Additionally, a thorough review of the screening protocols currently used before SMILE may illuminate areas for improvement using corneal biomechanical and wavefront principles. Until specific risk screening metrics for SMILE have been validated, caution should be exercised in patients with abnormal topography. For now, we recommend the same contraindication criteria for LASIK be adopted to the SMILE procedure.

\section{Data availability}

All data generated or analyzed during this study are included in the tables provided in this published review or referenced to the appropriate source.

\section{Acknowledgments}

This study was funded by an unrestricted grant from Research to Prevent Blindness (RPB), New York, NY, USA.

Editorial assistance in preparation of this manuscript was provided by Mitchell $\mathrm{T}$ Tingey of Brigham Young University, Andrew E Bean of the McGovern Medical School, and Yasmyne C Ronquillo, MD, of HDR Research, Hoopes Vision.

\section{Disclosure}

The authors report no conflicts of interest in this work.

\section{References}

1. Seiler T. [Iatrogenic corneal ectasia after LASIK - is the end in sight?]. Klin Monbl Augenheilkd. 2005;222(5):429.

2. Rad AS, Jabbarvand M, Saifi N. Progressive keratectasia after laser in situ keratomileusis. J Refract Surg. 2004;20(5 suppl):S718-S722.
3. Pallikaris IG, Kymionis GD, Astyrakakis NI. Corneal ectasia induced by laser in situ keratomileusis. J Cataract Refract Surg. 2001;27(11): 1796-1802.

4. Randleman JB. Evaluating risk factors for ectasia: what is the goal of assessing risk? J Refract Surg. 2010;26(4):236-237.

5. Randleman JB, Russell B, Ward MA, Thompson KP, Stulting RD. Risk factors and prognosis for corneal ectasia after LASIK. Ophthalmology. 2003;110(2):267-275.

6. Dupps WJ Jr. Ectasia risk: a multifactorial conundrum. J Cataract Refract Surg. 2015;41(4):699-700.

7. Moshirfar M, McCaughey MV, Reinstein DZ, Shah R, Santiago-Caban L, Fenzl CR. Small-incision lenticule extraction. J Cataract Refract Surg. 2015;41(3):652-665.

8. Ivarsen A, Asp S, Hjortdal J. Safety and complications of more than 1500 small-incision lenticule extraction procedures. Ophthalmology. 2014; 121(4):822-828.

9. Reinstein DZ, Carp GI, Archer TJ, Gobbe M. Outcomes of small incision lenticule extraction (SMILE) in low myopia. $J$ Refract Surg. 2014;30(12):812-818

10. Sekundo W, Kunert KS, Blum M. Small incision corneal refractive surgery using the small incision lenticule extraction (SMILE) procedure for the correction of myopia and myopic astigmatism: results of a 6 month prospective study. Br J Ophthalmol. 2011;95(3):335-339.

11. Vestergaard AH, Grauslund J, Ivarsen AR, Hjortdal JØ. Efficacy, safety, predictability, contrast sensitivity, and aberrations after femtosecond laser lenticule extraction. J Cataract Refract Surg. 2014;40(3): 403-411.

12. Blum M, Täubig K, Gruhn C, Sekundo W, Kunert KS. Five-year results of small incision lenticule extraction (ReLEx SMILE). Br J Ophthalmol. 2016;100(9):1192.

13. Randleman JB, Grossniklaus HE, Dawson DG, McCarey BE, Edelhauser HF. Depth-dependent cohesive tensile strength in human donor corneas: implications for refractive surgery. J Refract Surg. 2008; 24(1):S85-S89.

14. Reinstein DZ, Archer TJ, Gobbe M. The Key Characteristics of Corneal Refractive Surgery: Biomechanics, Spherical Aberration, and Corneal Sensitivity After SMILE, in Small Incision Lenticule Extraction (SMILE). Cham, Switzerland, Springer; 2015:123-142.

15. Yang E, Roberts C, Mehta J. A review of corneal biomechanics after LASIK and SMILE and the current methods of corneal biomechanical analysis. Clin Exp Ophthalmol. 2016;6:1-6.

16. Mattila JS, Holopainen JM. Bilateral ectasia after femtosecond laserassisted small incision lenticule extraction (SMILE). J Refract Surg. 2016; 32(7):497-500.

17. El-Naggar MT. Bilateral ectasia after femtosecond laser-assisted small-incision lenticule extraction. J Cataract Refract Surg. 2015;41(4): 884-888.

18. Wang Y, Cui C, Li Z, et al. Corneal ectasia 6.5 months after small-incision lenticule extraction. J Cataract Refract Surg. 2015;41(5):1100-1106.

19. Sachdev G, Sachdev MS, Sachdev R, Gupta H. Unilateral corneal ectasia following small-incision lenticule extraction. J Cataract Refract Surg. 2015;41(9):2014-2018.

20. Sinha Roy A, Dupps WJ Jr, Roberts CJ. Comparison of biomechanical effects of small-incision lenticule extraction and laser in situ keratomileusis: finite-element analysis. J Cataract Refract Surg. 2014;40(6): 971-980.

21. Wu D, Wang Y, Zhang L, Wei S, Tang X. Corneal biomechanical effects: small-incision lenticule extraction versus femtosecond laserassisted laser in situ keratomileusis. J Cataract Refract Surg. 2014;40(6): 954-962.

22. Jester JV, Winkler M, Jester BE, Nien C, Chai D, Brown DJ. Evaluating corneal collagen organization using high-resolution nonlinear optical macroscopy. Eye Contact Lens. 2010;36(5):260-264.

23. Seven I, Vahdati A, Pedersen IB, et al. Contralateral eye comparison of SMILE and flap-based corneal refractive surgery: computational analysis of biomechanical impact. J Refract Surg. 2017;33(7): $444-453$. 
24. Kling S, Hafezi F. Corneal biomechanics - a review. Ophthalmic Physiol Opt. 2017;37(3):240-252.

25. Binder PS, Trattler WB. Evaluation of a risk factor scoring system for corneal ectasia after LASIK in eyes with normal topography. J Refract Surg. 2010;26(4):241-250.

26. Reinstein DZ, Archer TJ, Randleman JB. Mathematical model to compare the relative tensile strength of the cornea after PRK, LASIK, and small incision lenticule extraction. J Refract Surg. 2013;29(7):454-460.

27. EuroTimes. Reasons to SMILE - interview with Dan Reinstein. In: Jacob S, editor. EYE Contact. European Society of Cataract and Refractive Surgeons (ESCRS); Dublin, Ireland, 2016.

28. Randleman JB, Woodward M, Lynn MJ, Stulting RD. Risk assessment for ectasia after corneal refractive surgery. Ophthalmology. 2008; 115(1):37-50.

29. Giri P, Azar DT. Risk profiles of ectasia after keratorefractive surgery. Curr Opin Ophthalmol. 2017;28(4):337-342.

30. Randleman JB, Trattler WB, Stulting RD. Validation of the ectasia risk score system for preoperative laser in situ keratomileusis screening. Am J Ophthalmol. 2008;145(5):813-818.
31. Santhiago MR, Smadja D, Gomes BF, et al. Association between the percent tissue altered and post-laser in situ keratomileusis ectasia in eyes with normal preoperative topography. Am J Ophthalmol. 2014;158(1): 87.e1-95.e1.

32. Santhiago MR, Giacomin NT, Smadja D, Bechara SJ. Ectasia risk factors in refractive surgery. Clin Ophthalmol. 2016;10:713-720.

33. Santhiago MR, Smajda D, Wilson SE, Randleman JB. Relative contribution of flap thickness and ablation depth to the percentage of tissue altered in ectasia after laser in situ keratomileusis. J Cataract Refract Surg. 2015;41(11):2493-2500.

34. Santhiago MR, Smadja D, Wilson SE, Krueger RR, Monteiro ML, Randleman JB. Role of percent tissue altered on ectasia after LASIK in eyes with suspicious topography. J Refract Surg. 2015;31(4):258-265.

35. Santhiago MR. Percent tissue altered and corneal ectasia. Curr Opin Ophthalmol. 2016;27(4):311-315.

36. Knox Cartwright NE, Tyrer JR, Jaycock PD, Marshall J. Effects of variation in depth and side cut angulations in LASIK and thin-flap LASIK using a femtosecond laser: a biomechanical study. J Refract Surg. 2012;28(6):419-425.

\section{Clinical Ophthalmology}

\section{Publish your work in this journal}

Clinical Ophthalmology is an international, peer-reviewed journal covering all subspecialties within ophthalmology. Key topics include: Optometry; Visual science; Pharmacology and drug therapy in eye diseases; Basic Sciences; Primary and Secondary eye care; Patient Safety and Quality of Care Improvements. This journal is indexed on

\section{Dovepress}

PubMed Central and CAS, and is the official journal of The Society of Clinical Ophthalmology (SCO). The manuscript management system is completely online and includes a very quick and fair peer-review system, which is all easy to use. Visit http://www.dovepress.com/ testimonials.php to read real quotes from published authors. 